\title{
Expression of Stem Cell Markers in Primo Vessel of Rat
}

\author{
Eun Seok Park, ${ }^{1}$ Jeong Hoon Lee, ${ }^{1}$ Won Jin Kim, ${ }^{1}$ Jinbeom Heo, ${ }^{2}$ \\ Dong Myung Shin, ${ }^{1,2}$ and Chae Hun Leem ${ }^{1}$ \\ ${ }^{1}$ Department of Physiology, University of Ulsan College of Medicine, 88 43-Gil Olympic-Ro, Songpa-gu, \\ Seoul 138-736, Republic of Korea \\ ${ }^{2}$ Department of Medicine, Graduate School, University of Ulsan, 88 43-Gil Olympic-Ro, Songpa-gu, Seoul 138-736, Republic of Korea
}

Correspondence should be addressed to Dong Myung Shin; d0shin03@amc.seoul.kr and Chae Hun Leem; leemch@gmail.com

Received 7 February 2013; Accepted 10 July 2013

Academic Editor: Byung-Cheon Lee

Copyright (C) 2013 Eun Seok Park et al. This is an open access article distributed under the Creative Commons Attribution License, which permits unrestricted use, distribution, and reproduction in any medium, provided the original work is properly cited.

\begin{abstract}
Accumulating line of evidence support that adult tissues contain a rare population of pluripotent stem cells (PSCs), which differentiate into all types of cells in our body. Bonghan microcell (primo microcells (PMCs)) discovered in 1960s was reported to have a pluripotency like a stem cell in vivo as well as in vitro condition. Here, we describe the detailed morphology and molecular features of PMCs. PMCs reside in Bonghan duct (primo vessel (PV)) reported as a corresponding structure of acupuncture points and meridian system. We found that PMCs were frequently observed in the liver surface of the rat between $300 \mathrm{~g}$ and $400 \mathrm{~g}$ from April to June, suggesting that the their detection frequency depends on the weight, the season, and the organ of rat. As reported, PMCs freshly isolated from PVs were spherical $\sim 1-2 \mu \mathrm{m}$ microsized cells. In contrast, a unique bithread or budding-shaped PMCs emerged during tissue culture around 8 days. RT-PCR analysis demonstrated that PVs-derived cells express the Oct4, the most important PSCs gene, in addition to several PSCs markers (Sox2, Stella, Rex1, and Klf4). Thus, we for the first time provide the evidence about Oct4-expressing stem-like characteristics for cells resident in PVs, a possible novel stem cell enriched niche.
\end{abstract}

\section{Introduction}

Continuous tissue and organ regeneration is one of the important homeostatic mechanisms of the multicellular organism. Homeostasis of adult tissues is regulated by a population of stem cells, which replace cells used up during life by undergoing self-renewal and maintaining their own pool. Stem cells are guardians of tissue/organ integrity and regulate the life span of an adult organism [1]. The most central stem cells, from a regenerative potential point of view, are pluripotent stem cells (PSCs). According to their definition, PSCs give rise to cells from all three germ layers in vitro and in vivo condition [2]. In contrast to differentiated somatic cells, PSCs commonly express pluripotent core transcription factors (TFs) such as Oct4, Nanog, and Sox2 that are essential to maintain their pluripotent state [2].

Typically, PSCs have been established from embryonic tissue (e.g., embryonic stem cells (ESCs)) and by the ectopic expression of reprogramming factors into the terminally differentiated adult cells (e.g., inducible PSC). However, recent evidence has accumulated demonstrating that PSCs may reside in adult tissues and are able to differentiate into tissue-committed stem cells (TCSCs) [1]. These cells have been variously described in the literature as (i) multipotent adult progenitor cells (MAPCs), (ii) marrow-isolated adult multilineage-inducible (MIAMI) cells, (iii) multipotent adult stem cell (MASCs), (iv) OmniCytes, (v) Dot cell, or (vi) very small embryonic-like (VSEL) stem cell [3-8]. It has been suggested that all these cells, described by different investigators as various names, could be closely related or could be overlapping stem cell populations. Thus, exploring their relationship could advance our understanding of biological process for their pluripotency and differentiation.

When adult stem cell research began in the 1960s, Kim claimed to discover the structures, Bonghan duct (primo vessel (PV)), and corpuscle (primo node), and reported as a corresponding structure of acupuncture points and meridian system [9]. In succession, he reported a Sanal (primo microcell (PMC)) which was spherical shape with the size of $0.8 \sim 2.4 \mu \mathrm{m}$ containing DNA and claimed that those 
cells flow in primo vessel. Most interestingly, he claimed that the Sanal had a pluripotency like a stem cell by showing the pluripotency evidenced by their dividing and differentiating into several types of tissue committed cells in vivo as well as in vitro condition [10]. Since the lack of a detailed procedure for the isolation/identification of PMCs, his results have been difficult to repeat. Thus, the Bonghan theory has been largely overlooked for many years, and PMCs were regarded just as a simple cellular debris/fragments or part of apoptotic bodies.

With advance of modern microscopy and molecular biology technologies, several researchers recently have reported the evidence for the existence of the Bonghan system inside blood or lymphatic vessels [11, 12], on the organ surface [13], and in the brain [14]. The PMCs have been also successfully isolated as DNA containing a spherical microsized $(1-2 \mu \mathrm{m}$ in diameter) cell from Bonghan systems on organ surfaces using a differential centrifugation method [15]. Observation under transmission electron (TEM) microscopy has revealed that PMCs have an inner ultrastructure of a $1.5 \mu \mathrm{m}$ sized central region and many small 50-500 $\mathrm{nm}$ sized granules in the peripheral region, which are distinguished from apoptotic bodies and other microorganisms [16]. While most of PMCs were round-shaped, some of them had a unique protrusion and possible proliferation feature, as protruding threads under atomic force microscopy (AFM) [16]. However, their precise cellular and molecular natures have remained to be determined.

In this paper, we isolated the primo vessel detected in rat abdomen and tracked the cellular changes using live cell imaging. And also, we investigated whether PVs express some molecular markers for PSCs such as Oct4, Sox2, Rex1, and Stella at the mRNA level. Thus, we propose that the PVs could be a potential container for the source of Oct4 expressing adult stem cells.

\section{Materials and Methods}

2.1. Isolation of $P V$ s and $P M C$. Sprague-Dawley rats (specific pathogen-free rat) aged 7-10 weeks were used. Procedures involving animals and their care conformed to institutional guidelines. Rats were anesthetized with intramuscular injection (Xylazine + ketamine, 1: 4 mixture, $0.4 \mathrm{~mL} / 100 \mathrm{~g}$ ). Under the anesthesia, the abdominal wall was carefully dissected along the linea alba without any bleeding into the abdomen because the coagulation thread was easily regarded as the primo vessel [17]. Under the stereomicroscope (XTL-5, Scienscope, USA), the organ surface was thoroughly examined to find PVs with the order of liver, stomach, spleen, small intestine, large intestine, and bladder. Even though there were many studies to report PVs, until now, the confirmation criteria of PVs in vivo are still obscure. Therefore, firstly, we tried to find the thread-like structure on the organ surface, which was not attached and easily lifted with the forceps. If it had a node structure, it was assumed as PVs. Secondly, on the inverted microscope, the tissues were examined whether the PMCs were incorporated in the nodes. If it had the PMCs of the size of $1 \sim 2 \mu \mathrm{m}$, we confirmed that the isolated tissues were PVs. Sometimes, we used an alcian blue (1\%) to
TABLE 1: Sequences of primers employed for RT-PCR and their anticipated PCR product size.

\begin{tabular}{|c|c|c|}
\hline \multirow{2}{*}{$\beta$-actin } & For-CATGGCATTGTGATGGACT & \multirow{2}{*}{$427 \mathrm{bp}$} \\
\hline & Rev-ACGGATGTCAACGTCACACT & \\
\hline \multirow{2}{*}{$\mathrm{cMyc}$} & For-GGGACAGTGTTCTCTGCCTCT & \multirow{2}{*}{$199 \mathrm{bp}$} \\
\hline & Rev-TTCTCTTCCTCGTCGCAGAT & \\
\hline \multirow{2}{*}{ Fbxo15 } & For-GTGGAGGAAACAGCCACA & \multirow{2}{*}{$306 \mathrm{bp}$} \\
\hline & Rev-ATGTGGCCAATTTTTGTCAT & \\
\hline \multirow{2}{*}{ Klf4 } & For-CAGTCGCAAGTCCССТСТCTC & \multirow{2}{*}{$321 \mathrm{bp}$} \\
\hline & Rev-CCTGTCGCACTTCTGGCACTG & \\
\hline \multirow{2}{*}{ Nanog } & For-GCCCTGAGAAGAAAGAAGAG & \multirow{2}{*}{$356 \mathrm{bp}$} \\
\hline & Rev-CGTACTGCCCCATACTGGAA & \\
\hline \multirow{2}{*}{ Nestin } & For-AGAGAAGCGCTGGAACAGAG & \multirow{2}{*}{$234 \mathrm{bp}$} \\
\hline & Rev-AGGTGTCTGCAACCGAGAGT & \\
\hline \multirow{2}{*}{ Oct4_PS\#1 } & For-GGGATGGCATACTGTGGAC & \multirow{2}{*}{$412 \mathrm{bp}$} \\
\hline & Rev-CTТССТССАСССАСТТСТС & \\
\hline \multirow{2}{*}{ Oct4_PS\#2 } & For-GATGGCATACTGTGGACCT & \multirow{2}{*}{$210 \mathrm{bp}$} \\
\hline & Rev-TTCATATCCTGGGACTCCTCG & \\
\hline \multirow{2}{*}{ Oct4_PS\#3 } & For-GGCTGGACACCTGGCTTCAGA & \multirow{2}{*}{$204 \mathrm{bp}$} \\
\hline & Rev-TGGTCCGATTCCAGGCCCA & \\
\hline \multirow{2}{*}{ Rexl } & For-TTCTTGCCAGGTTCTGGAAGC & \multirow{2}{*}{$297 \mathrm{bp}$} \\
\hline & Rev-TTTCССАСАСТСТGCACACAC & \\
\hline \multirow{2}{*}{ Sox 2} & For-GGCGGCAACCAGAAGAACAG & \multirow{2}{*}{$414 \mathrm{bp}$} \\
\hline & Rev-GTTGCTCCAGCCGTTCATGTG & \\
\hline \multirow{2}{*}{ Stella } & For-TCCTACAACCAGAAACACTAG & \multirow{2}{*}{$304 \mathrm{bp}$} \\
\hline & Rev-GTGCAGAGACATCTGAATGG & \\
\hline
\end{tabular}

facilitate the identification of PVs in vivo [18]. When the cells in PVs were cultured, high glucose DMEM (GIBCO, USA) contained $10 \%$ fetal bovine serum and $1 \%$ penicillin.

2.2. Reverse Transcriptase (RT) and Real-Time Quantitative $P C R$ (RQ-PCR). Total RNA from the PVs was isolated using the RNeasy Mini Kit (Qiagen Inc., Valencia, CA, USA) with removal of genomic DNA using the DNA-free Kit (Applied Biosystems, Foster City, CA, USA). The mRNA (10 ng) was reverse-transcribed with TaqMan Reverse Transcription Reagents (Applied Biosystems) according to the manufacturer's instructions. The resulting cDNA PCR fragments were amplified using AmpliTaq Gold at 1 cycle of $8 \mathrm{~min}$ at $95^{\circ} \mathrm{C}$, 2 cycles of $2 \mathrm{~min}$ at $95^{\circ} \mathrm{C}, 1 \mathrm{~min}$ at $60^{\circ} \mathrm{C}$, and $1 \mathrm{~min}$ at $72^{\circ} \mathrm{C}$ and subsequently by 35 cycles of $30 \mathrm{~s}$ at $95^{\circ} \mathrm{C}, 1 \mathrm{~min}$ at $60^{\circ} \mathrm{C}$, $1 \mathrm{~min}$ at $72^{\circ} \mathrm{C}$ and 1 cycle of $10 \mathrm{~min}$ at $72^{\circ} \mathrm{C}$, by using sequencespecific primers (Table 1). All primers were designed with Primer Express software (Applied Biosystems). The PCR products were separated by $1.5 \%$ agarose gel electrophoresis.

2.3. Statistical Analysis. All the data in RQ-PCR analyses were analyzed using Student's $t$ test or one-way ANOVA with Bonferroni posttests. We used the GraphPad Prism 5.0 program (GraphPad Software, La Jolla, CA, USA), and statistical significance was defined as $P<0.05$ or $P<0.01$. 


\section{Result and Discussion}

Figure 1 showed the thread-like structures presumed PVs on organ surface such as liver, small intestine, and spleen, respectively. As shown in Figure 1, the isolated PVs, threadlike structures were easily lifted with forceps which was the most important discrimination from blood vessel or lymphatic vessel.

Next, we examined the morphologic change during maintaining the PMCs under tissue culture condition for 8 days. Most of cultured PMCs remained as spherical microsized cell $(\sim 1-2 \mu \mathrm{m}$ sized) as similar to freshly isolated ones (Figure 2(a)). Of particular, some of the cultured PMCs showed a unique bithread shape or budding (Figure 2(b)). This transformation is similar to PMCs budding previously described by Kim $[9,10]$. According to his observations, PMCs make a protrusion-like thread and produce a daughter microcell from that thread to make proliferation $[9,10]$. Thus, this observation may suggest that the culture of PMCSs could promote their proliferation potency. As other expectations, this thread-like structure might be established to transfer small molecules like microvesicle [19] or to provide a polarized tension for other biological processes like migration or asymmetrical differentiation.

PMCs were not identified in all rats, and the detection rate of PMCs was $24 \%$ (39 rat detected/165 rat tested). When we performed the experiments, we felt that the detection rate of PMCs was changed depending on weight and the season. We summarized the frequency for the detection of PMCs in the condition of different weight and tissue origin in rat (Figure 3). The detection rate of PMCs was the highest in the rats weighed between $300 \mathrm{~g}$ and $400 \mathrm{~g}$, about $32 \%$. If the weight of rat was over $400 \mathrm{~g}$, the detection rate was about $6 \%$, and if under $300 \mathrm{~g}$, the detection rate was about $17 \%$. Moreover, we found the seasonal variation of the detection of PMCs. The PMCs were more frequently found from April to June about $40 \%$. The PMCs were most frequently found on the liver surface more than $70 \%$ and the least found on the large intestine about $5 \%$. The earlier results suggested the guidance of the rat choice. To facilitate finding PMCs, the rats of the weight between $300 \mathrm{~g}$ and $400 \mathrm{~g}$ were used during the spring, and the surface of liver must be firstly examined.

To better understand the molecular insight of cells in PVs, we examined the expression of PSCs-specific genes in whole extracts from PVs. First, we tried to examine the expression of Oct4, the most important transcription factor for maintaining stem cell pluripotency using three independent primer sets. As shown in Figure 4(a), a PCR reaction using all the primer sets amplified transcript for Oct4 specifically in the PV, but not in cells from adult whole blood. Since PSCs also express Nanog, Sox2, and Fbxo15, we evaluated their expression in PVs. They express only Sox2, but they do not express Nanog and Fbxo15 (Figure 4(b)). The Sox2 and Nanog transcripts were not expressed in whole blood cells. Next, we also examine the expression level of Stella, Rexl, and Klf4, highly expressed in inner cell mass primitive PSCs [20]. We noticed that PVs specifically expressed these PSC markers, which all support their pluripotent character (Figure 4(c)). In contrast, the transcript of Nestin, a neural stem cell marker, was not detected in any PVs tested (Figure 4(d)). Of particular, the expression of cMyc was different between PVs, representing the heterogenous features for their cell proliferation potency (Figure 4(d)). Taken together, this result provides the evidence that PVs contain the Oct4 expressing stem cell-like population, which could function as a back-up/reserve source for Oct $4^{+}$PSCs in adult tissues.

Lack of a detail description for the isolation and identification of PVs has been a main hurdle to get the reproducible observation of PVs. In the present study, we demonstrate that the PMCs were more frequently found from the SD rat weighed between $300 \mathrm{~g}$ and $400 \mathrm{~g}$. Moreover, we found the seasonal variation, and most PMCs were found during the spring (April, May, and June). The liver surface was the preferred location of PMCs detection. Since we confirmed PVs when it contained microcells, PV detection rate without PMCs was not examined. Even though we did not present the detection rate during winter (from January to March), some trials during January showed that the winter season might be the worst to find PVs with PMCs (0/12 cases).

Most of PMCs prepared from PVs show the round 1$2 \mu \mathrm{m}$ microsized morphological features, and they form the unique thread-like structure or budding during tissue culture condition. Moreover, cells resident in these PVs express the most of PSCs-specific transcripts, suggesting that they might be novel explanation about the detection of PSCs markers from adult tissues. Thus, further investigation using highly purified cells of PVs should be necessary to identify which cells in PVs could show the Oct4 expressing stem cell-like features in a molecular and cellular context, and PMCs may be the highest probable candidate having the stem cell nature.

Present study proves that the PVs express the transcripts for PSCs (Figure 4). However, several questions remain to be addressed regarding these rare microsized cells. First, their developmental origin is unresolved. It has been considered that PSCs during embryogenesis/gastrulation may become eliminated after giving rise to TCSCs, or conversely, they may survive among TCSCs and serve as a back-up/reserve source for these cells [1]. Thus, it is important to elucidate whether PMCs are functional under steady-state conditions or are merely remnants from developmental embryogenesis that loses the potency of tissue regeneration. Second, the question is about the microsize of the PMCs. Most of PMCSs were around 1-2 $\mu \mathrm{m}$ in diameter, which is smaller than normal human haploid sperm head $(\sim 2.5-3 \mu \mathrm{m})$. This might suggest that PMCs could contain whole parts of cell organelles. Indeed, it was reported that DNA content of PMCs was around the chromosome-sized $10^{8} \mathrm{bps}$, and their DNA was fragmented $[9,10]$. Thus, it is possible that PMCSs might be similar to microvesicles (MVs), small circular membrane fragments shed from the cell surface or released from the endosomal compartment.

Due to small size, MVs also have been regarded just as simple cellular debris/fragments or part of apoptotic bodies. However, accumulating lines of evidence have reported that these tiny membrane fragments play an important and underappreciated role in cell-to-cell communication [21-23]. First, MVs may stimulate target cells directly by surfaceexpressed ligands acting as a kind of "signaling complex." 


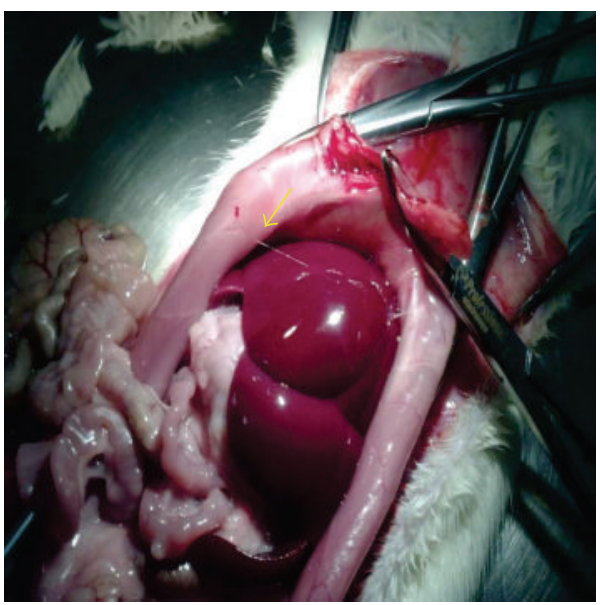

(a)

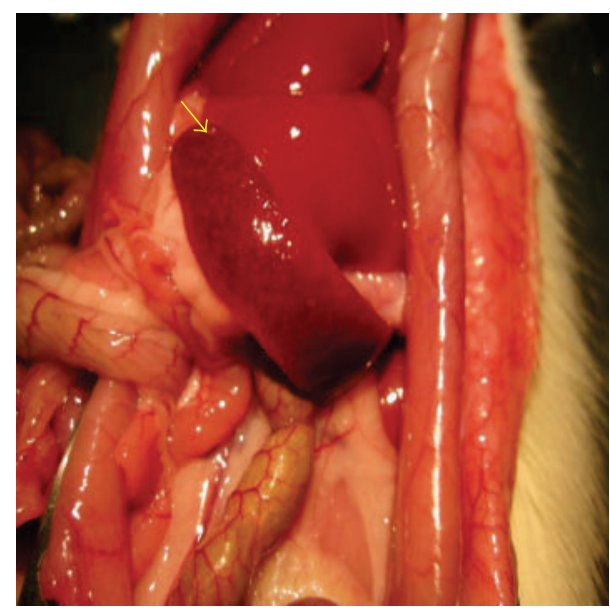

(c)

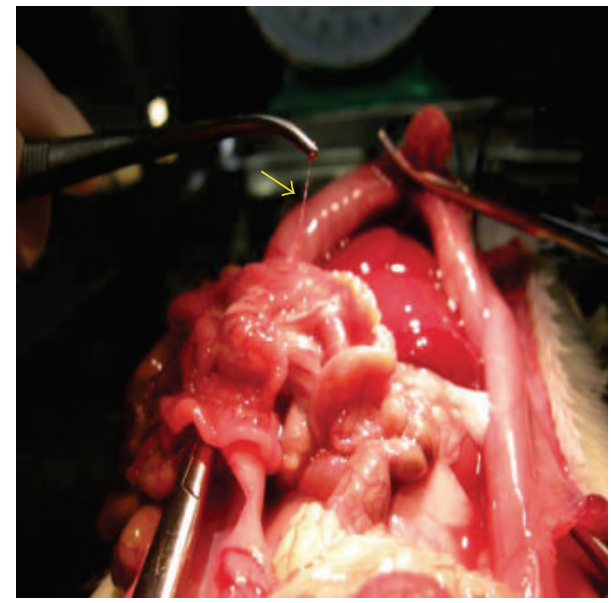

(b)

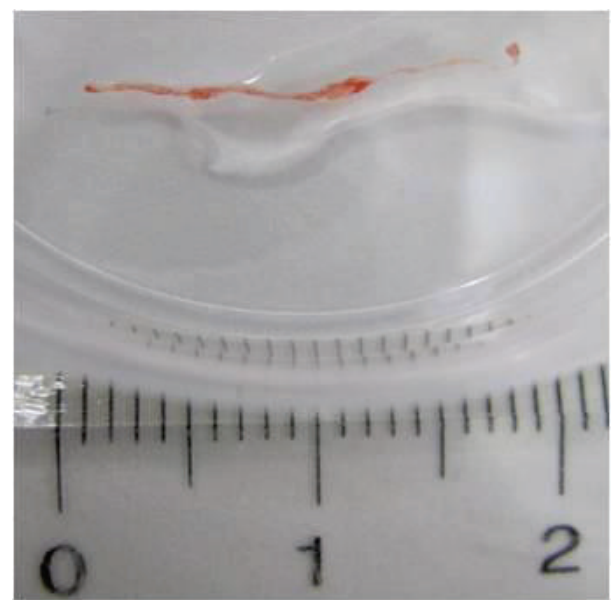

(d)

FIGURE 1: Detection of PVs on the surface of several organs. Thread-like structures presumed as PVs (arrow) were observed on organ surface such as liver (a), small intestine (b), and spleen (c). Representative photo of the isolated PV for further isolation of PMCs (d).

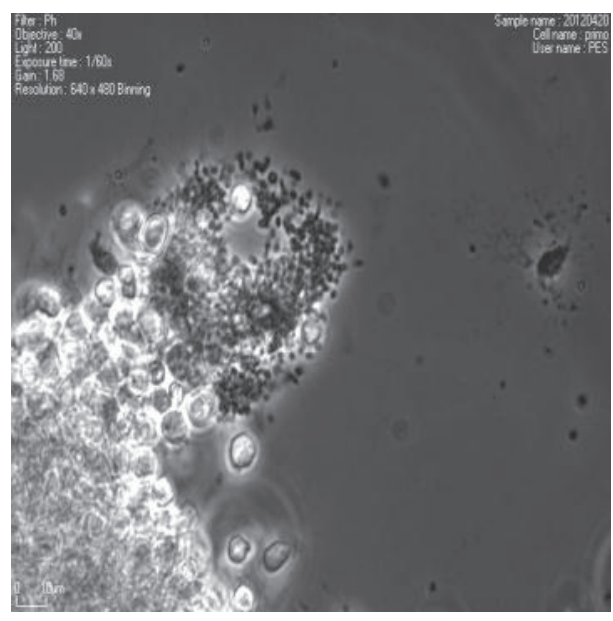

(a)

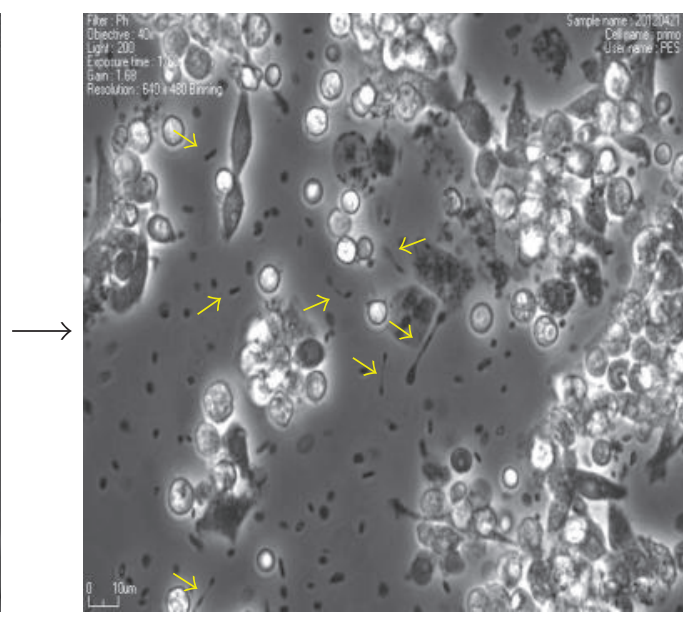

(b)

FIGURE 2: Morphologic change during tissue culture of PMCs. Representative pictures of PMCs tissue-cultured for 1 day (a) and 8 days (b). Most of PMCs at 1 day of tissue culture remained as spherical microsized cell ( 1-2 $\mu \mathrm{m}$ sized). Particularly, a unique bithread or buddingshaped PMCs (arrows in (b)) were observed after one week. 


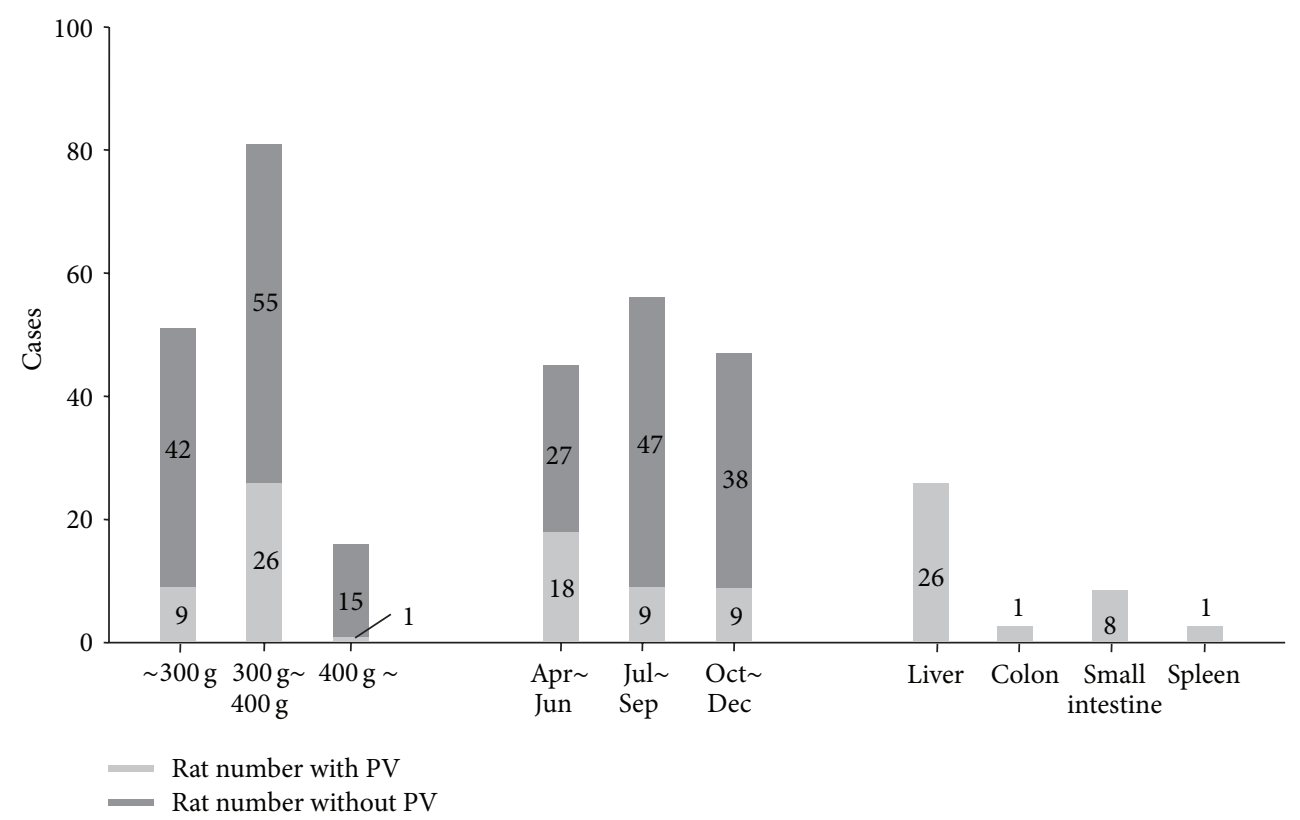

FIGURE 3: Detection rate of PMCs depends on rat weight and season. Frequency for detection of PMCs in the condition of the different weight, the season, and the organ in rat. Note that PMCs were frequently observed in the liver surface of the rat between $300 \mathrm{~g}$ and $400 \mathrm{~g}$ from April to June.

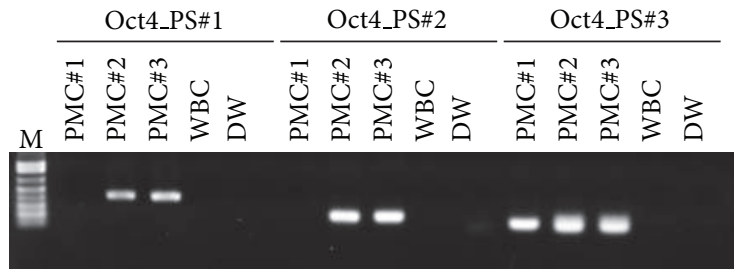

(a)

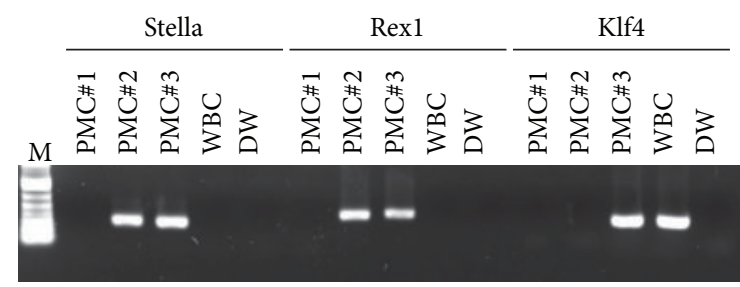

(c)

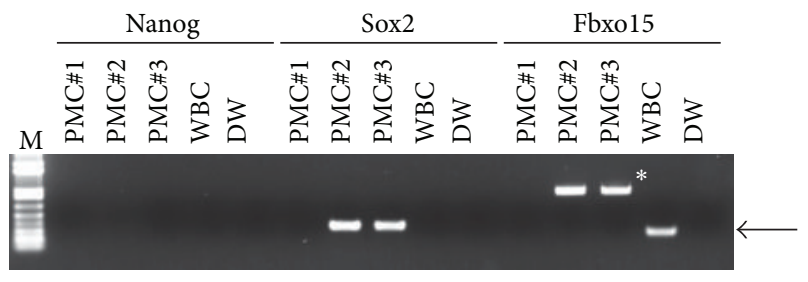

(b)

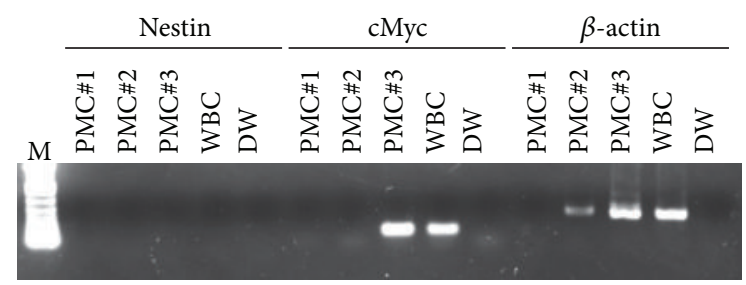

(d)

FIGURE 4: The expression of stem cell-related genes in PMCs. RT-PCR analysis of Oct4 (a), PSCs (b), ICM-enriched (c), neural stem cells, and $c M y c$ (d) genes in freshly isolated PMCs and whole blood cells (WBC). $\beta$-actin was used as an endogenous housekeeping gene. Control reaction was performed without template (DW, distilled water). Arrow and asterisk in Fbxo15 part represent the expectedly sized and nonspecific PCR product, respectively. M: DNA size marker.

Second, they might transform the neighboring cells by transferring surface receptors and delivering proteins, mRNA, bioactive lipids, and even whole organelles (e.g., mitochondria). Finally, they may also serve as a vehicle to transfer infectious particles between cells such as prions or HIV. Thus, investigating the relationship between PMCs and MVs could not only advance our understanding of these microsized biocomponents but also their application in stimulating the therapeutic potency of adult stem cells.

\section{Conclusions}

Herein, we report that PVs are frequently detected in rat grown to a weight between $300 \mathrm{~g}$ and $400 \mathrm{~g}$. Moreover, we found the seasonal variation to detect PMC, and the spring is the best season to detect PVs. PVs were more frequently found on the liver surface than the other internal abdominal organs. And also, we provide the cellular characteristics of PMCs and the molecular characteristics of PVs. 
We, for the first time, provide the evidence about Oct4expressing stem-like characteristics for cells resident in PVs, a possible novel stem cell enriched niche. Thus, functional research about their tissue regeneration potency would be essential for providing the biological significance of PVs and PMCs, especially in the field of stem cell and cancer biology.

\section{Conflict of Interests}

The authors declare that they have no financial conflict of interests.

\section{Acknowledgments}

The authors thank Dr. Lee BC in KAIST and Professor Soh KS in SNU for the helpful advice about the primo vascular system. This research was partly supported by a grant from the Korea Institute of Oriental Medicine (K12272), by a grant from the National Research Foundation (20120009829) to C. H. Leem, and by a grant from the Korean Health Technology R\&D Project, Ministry of Health \& Welfare, Republic of Korea (A120301) to D. M. Shin.

\section{References}

[1] M. Z. Ratajczak, B. Machalinski, W. Wojakowski, J. Ratajczak, and M. Kucia, "A hypothesis for an embryonic origin of pluripotent Oct- $4^{+}$stem cells in adult bone marrow and other tissues," Leukemia, vol. 21, no. 5, pp. 860-867, 2007.

[2] H. Niwa, "How is pluripotency determined and maintained?" Development, vol. 134, no. 4, pp. 635-646, 2007.

[3] Y. Jiang, B. N. Jahagirdar, R. L. Reinhardt et al., "Pluripotency of mesenchymal stem cells derived from adult marrow," Nature, vol. 418, no. 6893, pp. 41-49, 2002.

[4] G. D'Ippolito, S. Diabira, G. A. Howard, P. Menei, B. A. Roos, and P. C. Schiller, "Marrow-isolated adult multilineage inducible (MIAMI) cells, a unique population of postnatal young and old human cells with extensive expansion and differentiation potential," Journal of Cell Science, vol. 117, no. 14, pp. 2971-2981, 2004.

[5] R. R. Pochampally, J. R. Smith, J. Ylostalo, and D. J. Prockop, "Serum deprivation of human marrow stromal cells (hMSCs) selects for a subpopulation of early progenitor cells with enhanced expression of OCT-4 and other embryonic genes," Blood, vol. 103, no. 5, pp. 1647-1652, 2004.

[6] A. P. Beltrami, D. Cesselli, N. Bergamin et al., "Multipotent cells can be generated in vitro from several adult human organs (heart, liver, and bone marrow)," Blood, vol. 110, no. 9, pp. 34383446, 2007.

[7] M. Kucia, R. Reca, F. R. Campbell et al., "A population of very small embryonic-like (VSEL) CXCR $4^{+}$SSEA- $1^{+}$Oct- $4^{+}$stem cells identified in adult bone marrow," Leukemia, vol. 20, no. 5, pp. 857-869, 2006.

[8] M. Kucia, M. Halasa, M. Wysoczynski et al., "Morphological and molecular characterization of novel population of CXCR $4^{+}$ SSEA $-4^{+}$Oct $-4^{+}$very small embryonic-like cells purified from human cord blood-preliminary report," Leukemia, vol. 21, no. 2, pp. 297-303, 2007.

[9] B. H. Kim, "On the Kyungrak system," Journal of Academy of Medical Sciences, DPR Korea, pp. 1-41, 1963.
[10] B. H. Kim, “The Kyungrak system and Sanal theory," Journal of Academy of Medical Sciences, DPR Korea, pp. 1-62, 1965 (Korean).

[11] B.-C. Lee, K. Y. Baik, H.-M. Johng et al., "Acridine orange staining method to reveal the characteristic features of an intravascular threadlike structure," Anatomical Record B, vol. 278, no. 1, pp. 27-30, 2004.

[12] B.-C. Lee, J. S. Yoo, K. Y. Baik, K. W. Kim, and K.-S. Soh, "Novel threadlike structures (Bonghan ducts) inside lymphatic vessels of rabbits visualized with a Janus Green B staining method," Anatomical Record B, vol. 286, no. 1, pp. 1-7, 2005.

[13] H.-S. Shin, H.-M. Johng, B.-C. Lee et al., "Feulgen reaction study of novel threadlike structures (Bonghan ducts) on the surfaces of mammalian organs," Anatomical Record B, vol. 284, no. 1, pp. 35-40, 2005.

[14] B.-C. Lee, S. Kim, and K.-S. Soh, "Novel anatomic structures in the brain and spinal cord of rabbit that may belong to the Bonghan system of potential acupuncture meridians," JAMS Journal of Acupuncture and Meridian Studies, vol. 1, no. 1, pp. 29-35, 2008.

[15] V. Ogay, K. Y. Baik, B.-C. Lee, and K.-S. Soh, "Characterization of DNA-containing granules flowing through the meridianlike system on the internal organs of rabbits," Acupuncture and Electro-Therapeutics Research, vol. 31, no. 1-2, pp. 13-31, 2006.

[16] K. Y. Baik, V. Ogay, S. C. Jeoung, and K.-S. Soh, "Visualization of bonghan microcells by electron and atomic force microscopy," JAMS Journal of Acupuncture and Meridian Studies, vol. 2, no. 2, pp. 124-129, 2009.

[17] C.-J. Choi and C.-H. Leem, "Comparison of the primo vascular system with a similar-looking structure," in The Primo Vascular System, K.-S. Soh, K. A. Kang, and D. K. Harrison, Eds., pp. 107113, Springer, New York, NY, USA, 2012.

[18] J. S. Yoo, M. S. Kim, V. Ogay, and K.-S. Soh, "In vivo visualization of Bonghan ducts inside blood vessels of mice by using an Alcian blue staining method," Indian Journal of Experimental Biology, vol. 46, no. 5, pp. 336-339, 2008.

[19] J. Ratajczak, M. Wysoczynski, F. Hayek, A. JanowskaWieczorek, and M. Z. Ratajczak, "Membrane-derived microvesicles: important and underappreciated mediators of cell-tocell communication," Leukemia, vol. 20, no. 9, pp. 1487-1495, 2006.

[20] D.-M. Shin, R. Liu, I. Klich et al., "Molecular signature of adult bone marrow-purified very small embryonic-like stem cells supports their developmental epiblast/germ line origin," Leukemia, vol. 24, no. 8, pp. 1450-1461, 2010.

[21] M. Z. Ratajczak, M. Kucia, T. Jadczyk et al., "Pivotal role of paracrine effects in stem cell therapies in regenerative medicine: can we translate stem cell-secreted paracrine factors and microvesicles into better therapeutic strategies?" Leukemia, vol. 26, pp. 1166-1173, 2012.

[22] M. Z. Ratajczak, "The emerging role of microvesicles in cellular therapies for organ/tissue regeneration," Nephrology Dialysis Transplantation, vol. 26, no. 5, pp. 1453-1456, 2011.

[23] R. Liu, I. Klich, J. Ratajczak, M. Z. Ratajczak, and E. K. ZubaSurma, "Erythrocyte-derived microvesicles may transfer phosphatidylserine to the surface of nucleated cells and falsely "mark" them as apoptotic," European Journal of Haematology, vol. 83, no. 3, pp. 220-229, 2009. 


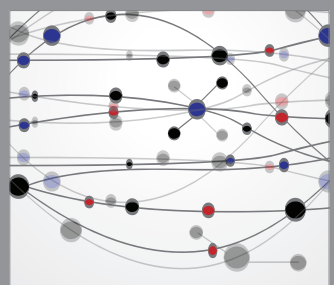

The Scientific World Journal
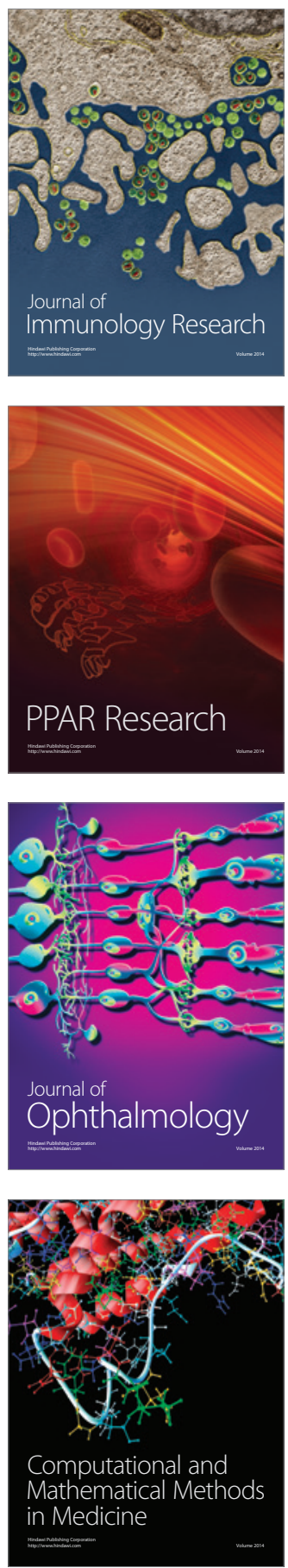

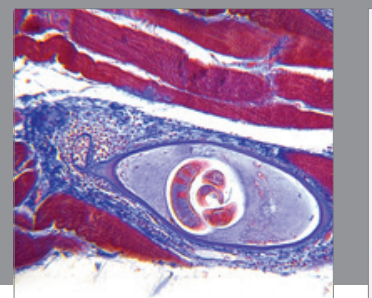

Gastroenterology

Research and Practice
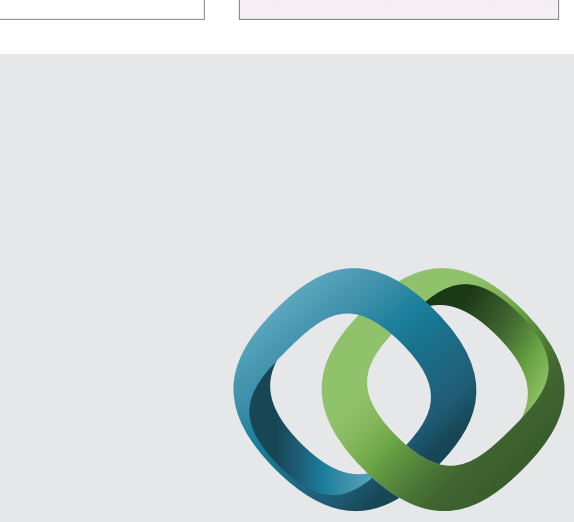

\section{Hindawi}

Submit your manuscripts at

http://www.hindawi.com
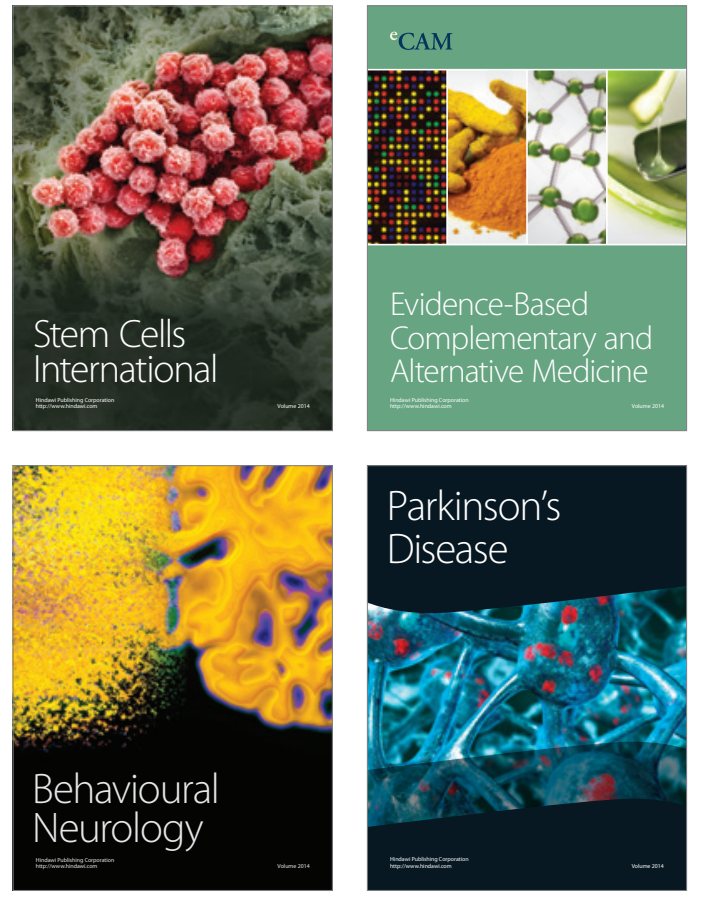
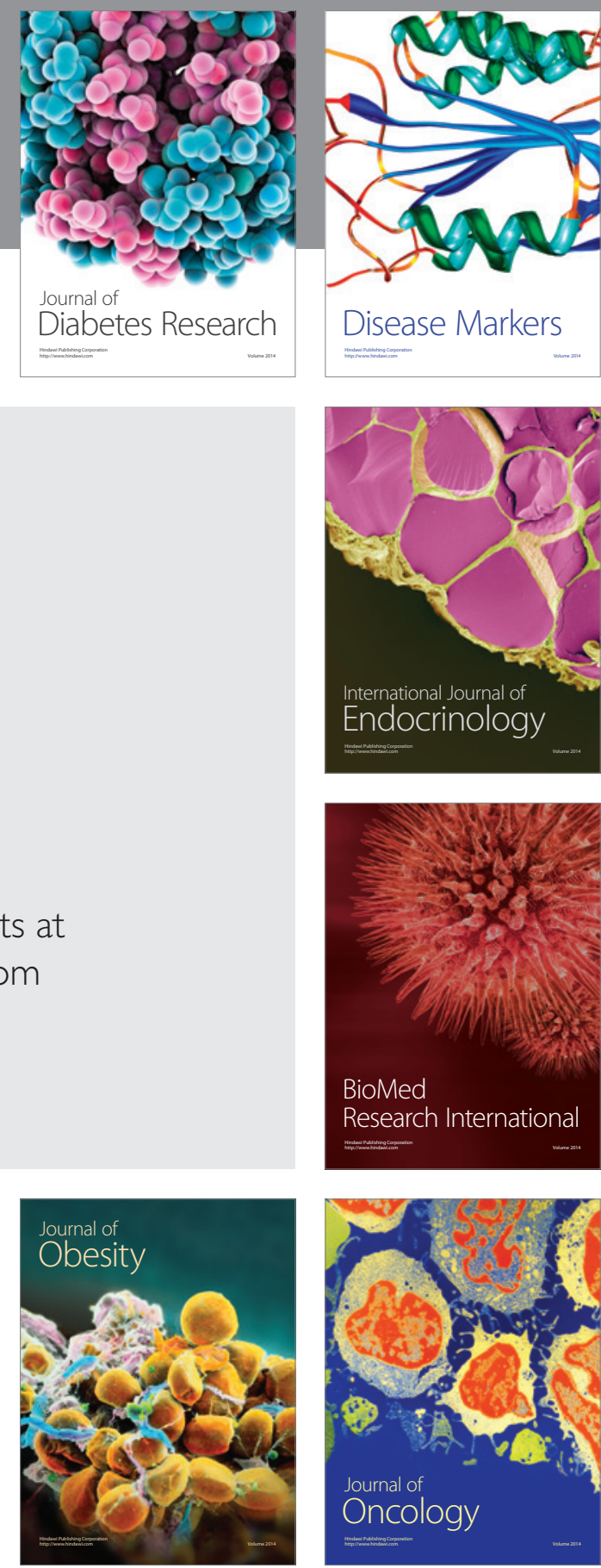

Disease Markers
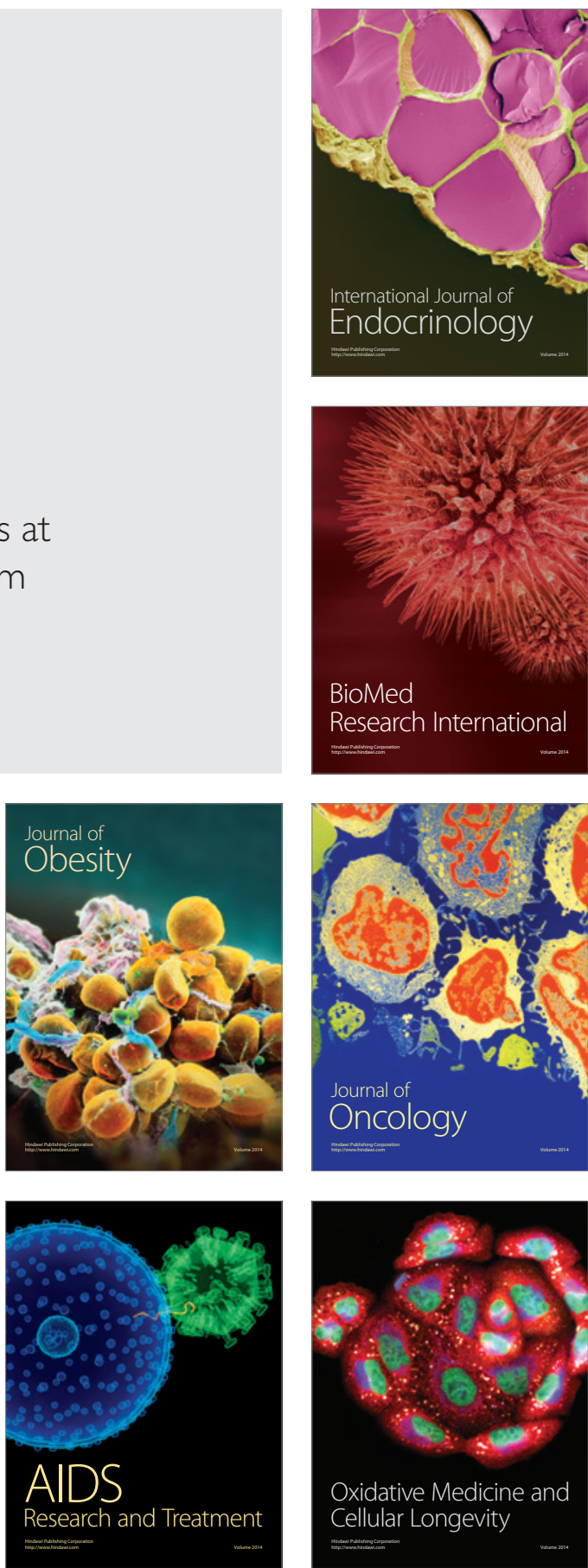